\title{
Cylindro-Conical Mild Steel Projectile Impact on E-Glass Fiber Reinforced Laminated Composite Plate Including Delamination Analysis
}

\author{
Hande Yavuz ${ }^{1 *}$ \\ University of Turkish Aeronautical Association, Department of Astronautical Engineering, Ankara, Turkey
}

\begin{abstract}
Computational impact analysis of an E-glass fiber reinforced laminated composite structure with a conical nose shaped projectile is performed including delamination analysis. In addition to intralaminar damage analysis, interlaminar damage analysis is considered due to the laminated configuration of the protective structure. Threat is made of mild steel projectile and it is modeled using Johnson-Cook material model with ductile damage criterion. Intralaminar and interlaminar damage modeling of target material is realized in the frame of Hashin damage criteria and quadratic nominal stress criterion with Benzeggagh-Kenane fracture criterion, respectively. Stress and damage distribution both in target and threat materials are obtained by mesh gradation analysis via Abaqus/Explicit v6.19. Effect of delamination analysis in computational impact modeling is evaluated by considering the computational cost regarding CPU time and wall clock time. Larger von Mises stresses obtained when excluding interlaminar debonding in the analysis. It is found that delamination analysis significantly improved the damage evaluation of composite laminates owing to impact loading with small computational effort.
\end{abstract}

Keywords: Ballistics, computational analysis, dynamic material behavior, polymer composites, delamination analysis.

\section{INTRODUCTION}

The multidisciplinary nature of ballistic impact involves highly complex phenomena. Stress wave propagation in solid structures, plastic deformation in materials, fracture mechanics, contact mechanics, and thermodynamics are the involving disciplines in ballistic impact phenomena [1]. In order to explore the ballistic impact phenomena, internal ballistics, external ballistics, and terminal ballistics would be specified accordingly. Internal ballistics considers the ignition process of the propellant, pressurization of the chamber, first motion event of the projectile, obturation of the chamber, in-bore dynamics of projectile, and tube dynamics during the firing cycle $[1,2]$. External ballistics come onto the stage with the flight movement of the projectile until the target after leaving of the projectile and gunpowder burning gases to the barrel. Terminal ballistics roughly deals with the interaction between the projectile and the target. Studying the theories of kinetic energy penetration of solid targets, burning of energetic materials, fragmentation theories, and blast effect would be some of crucial subjects to understand the terminal ballistics $[1,2]$. Other than these three ballistics disciplines, wound ballistics would be embedded in the lethality research in order to realize the impact of a projectile along with its possible effects on the human body $[1,3]$.

Ballistic impact has two fundamental classifications in terms the application area: (1) military and (2) general engineering. In general engineering applications, low/moderate velocity impact includes the striking velocity that is smaller than $50 \mathrm{~m} / \mathrm{s}$; high velocity impact includes the striking velocity that is between $50 \mathrm{~m} / \mathrm{s}$ and $1500 \mathrm{~m} / \mathrm{s}$; hyper velocity impact includes the striking velocity that is larger than 1500 $\mathrm{m} / \mathrm{s}$. Velocity ranges are rather higher in military applications and classified with ordnance terms [1]. While dealing with the development of protective structures concerning terminal ballistics metrics, one would consider the statistical parameters that are used to define the velocity at which a projectile -cause failure in a target. In this respect, $\mathrm{V}_{10}(10$ $\%$ penetration velocity), $V_{90}$ (90\% penetration velocity), and frequently $\mathrm{V}_{50}$ (50\% penetration velocity; ballistic limit) are used due the stochastic nature of penetration process. The failure modes of target such as scabbing, plugging, petaling, fragmentation, and even combined failure modes depends 
on the striking velocity and the thickness of the target. Moreover, blunt projectiles are known to cause plugging while conical projectiles are found to cause petaling [1]. Hence, the impact velocity, as well as the geometry and the dimensions of projectile and target play significant role in design of protective structures. The weight of protection systems is also one of the most relevant parameters to be tailored in order to provide necessary space for the functional implementations in engineering applications.

Ballistic protective structures could be constructed using metal alloys (e.g., BR7 class steel) [4], ceramics (e.g., $\mathrm{B}_{4} \mathrm{C}$ ) [5], and composite materials (e.g., aramid reinforced composites) [6]. In general, fiber reinforced composites withstand against the penetration of threat by dissipating its energy via different modes of failure mechanisms such as fiber fracture, fiber pull out, fiber split, fiber-matrix debonding, matrix cracking [7]. The delamination mode of failure of fiber reinforced composites due to interlaminar stresses is also a critical failure mode in many composite laminates. In macro-level failure mechanisms, each laminate is assumed to be homogenous and orthotropic with known strengths for one-dimensional states of stress in the principal material directions. Thus, when applying macroscopic level failure theories to each layer of laminate, first-ply failure theory corresponds to the fact that laminate fails when the first ply fails. However, the laminated nature of fiber-reinforced composites would not necessarily dictate the final failure that is only limited by the first ply failure [7]. These laminated materials may exhibit many local failures prior to rupture, which may alternatively to be referred as damage. It would be possible that some layers fail first and the composite continues to take load until all plies fail. Hybrid structures, which consist of a combination of more than one type of layer or fabric, have been studied for decades [8]. Researchers found that when Spectra 1000 layer backs Kevlar 29 layer, the ballistic limit was found $269 \mathrm{~m} / \mathrm{s}$, but it was only $114 \mathrm{~m} / \mathrm{s}$ when Kevlar 29 layer backs the Spectra 1000 layer [9]. The reason behind the difference in ballistic limit has been revealed by the dissimilar mechanical properties of materials when used as strike face; that is the transverse deflection of the two-ply system is constrained when Kevlar 29 backs the Spectra 1000 layer.

Ballistic impact modeling is greatly important while dealing with protection issues of an aircraft from various threats as well [10]. The design of sacrificial shield against space debris impact is essentially important for a spacecraft [11]. There are various materials and material combinations available to build protective structures against such threats. Rather than homogeneous monolithic materials, polymer matrix composites are treated as one of the candidate materials in order to increase ballistic performance of the protective structures [12]. Especially, the use of composite materials as a protective layer has crucial importance in aerospace field due to the mass criterion as well [13]. However, design limiting conditions such as environmental effects must be considered besides the mass criteria. In this study, interlaminar and intralaminar failure analyses of composite plates due to impact of a mild steel projectile at a velocity of $54 \mathrm{~m} / \mathrm{s}$ are performed by using Abaqus/Explicit v6.19. The cylindro-conical mild steel projectile is modeled by referring Johnson-Cook material model and ductile damage model. Deformation of E-glass fiber reinforced composite plate is computationally analyzed and compared with the data obtained from literature. Embedment of delamination analysis notably improved the failure behavior of composite plate that is subjected to impact loading.

\section{MATERIALS AND METHODS}

The impact modeling of E-glass fiber reinforced laminated composite flat plate (target) by mild steel projectile (threat) is performed by using Abaqus/Explicit v6.19. There are two methods of numerical time integration alternatives used in computational ballistics: (1) explicit, (2) implicit. The explicit time integration scheme provides solutions whatever the velocity of impact or the magnitude of the strain rates concerned $[14,15]$. However, implicit time integration scheme is treated less common compared to the explicit method for general impact problems [15]. Explicit method solves dynamic equilibrium equation and advance in time via Newmark integration method (including modification in equilibrium equation introduced by Hilber [16]) while explicit method implements central difference method accordingly. The values at the subsequent time step are computed directly in explicit method which makes it preferable over standard implicit method.

Finite element model of the study is comprised of two main constituents: (1) mild steel projectile and (2) laminated composite flat plate. Dimensional data of the projectile is given as follows: the total length is $99.5 \mathrm{~mm}$; the length of cylindrical shank is $46 \mathrm{~mm}$; the length of conical nose is $53.5 \mathrm{~mm}$; the angle of cone is $35.5^{\circ}$; and the radius of nose-tip is $19.63 \mathrm{~mm}$. The composite plate is of rectangular shape with dimensions $120 \mathrm{~mm} \times 120 \mathrm{~mm}$ and it has $6.20 \mathrm{~mm}$ thickness [15, 17]. The thickness of each composite ply in composite plate is $0.155 \mathrm{~mm}$ and all those plies are stacked at $0^{\circ}$ orientations. Target is fixed from its edges and finite element model of the study is represented in Figure 1. Finite element model of the projectile and plate are generated using C3D8R and SC8R elements, respectively. COH3D8 elements are used for the delamination analysis. Twenty finite element models are generated by using various mesh densities for numerical convergence. Five different mesh sizes (i.e., $1 \mathrm{~mm}, 1.25$ $\mathrm{mm}, 1.50 \mathrm{~mm}, 1.75 \mathrm{~mm}$, and $2 \mathrm{~mm}$ ) are attributed to each constituent of the finite element model. The corresponding total number of elements at given mesh sizes are as follows: for C3D8R (102144, 49840, 27353, 19880, 13968), for SC8R (14400, 9216, 6400, 4761, 3600), and for COH3D8 (14400, $9216,6400,4761,3600)$. The striking velocity of the cylindrical shank conical nose shaped projectile is $54 \mathrm{~m} / \mathrm{s}$. Each finite element model is computationally analyzed for a time 
Table 1. Johnson-Cook Material Model of Mild Steel [18]

\begin{tabular}{|c|c|c|c|c|c|c|c|}
\hline Density (kg/m3) & 7800 & Initial yield stress, A ( $\mathrm{MPa})$ & 153.82 & $\begin{array}{c}\text { Thermal Softening Expo- } \\
\text { nent, } \mathrm{m}\end{array}$ & 0.7 & $\begin{array}{l}\text { Strain Rate } \\
\text { Coefficient, C }\end{array}$ & 0.02 \\
\hline $\begin{array}{l}\text { Young's Modu- } \\
\text { lus (GPa) }\end{array}$ & 200 & $\begin{array}{l}\text { Strain Hardening Coeffi- } \\
\text { cient, } \mathrm{B}(\mathrm{MPa})\end{array}$ & 463.82 & Melting Temperature (K) & 1600 & $\begin{array}{l}\text { Reference Strain } \\
\text { Rate, } \dot{\varepsilon}_{0}\end{array}$ & 0.0001 \\
\hline Poisson's Ratio & 0.33 & $\begin{array}{c}\text { Strain Hardening Expo- } \\
\text { nent, } \mathrm{n}\end{array}$ & 0.37 & Temperature (K) & 300 & & \\
\hline
\end{tabular}

duration of $0.1 \mathrm{~ms}$. According to the defined velocity ranges for ballistic impact, it would be classified under high velocity impact regime when the general application is considered. The deformation processes depend on a large series of parameters besides impact velocity mostly. Hence, the transition in the ranges of the impact velocities should also be considered with caution $[14,15]$.

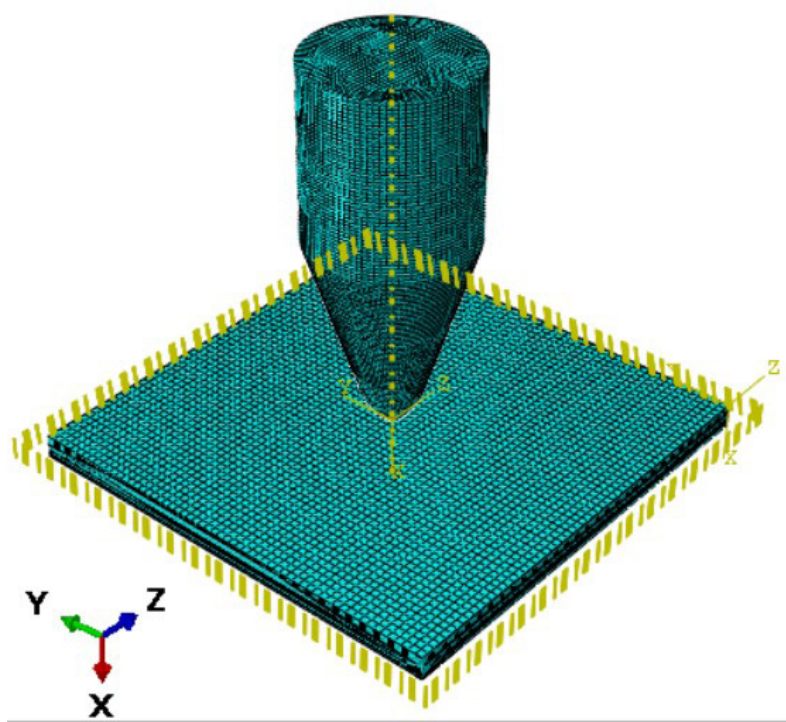

Figure 1. Representative Finite Element Model of the Composite Plate and Projectile

Johnson-Cook material model and ductile damage model for the projectile are adopted and their corresponding parameters are tabulated in Table 1 and Table 2, respectively [18]. Johnson-Cook material model is one of the most commonly used material model for the computation of yield stress for ductile metals [15]. The corresponding equation is represented in Equation 1. Here, $A, B, C$, $n$, and $m$ are essentially termed material parameters as mentioned in Table 1. $T^{*}$ is the normalized temperature $\left(T^{*}=\frac{T-T_{r}}{T_{m}-T_{T}}\right)$ and it is computed based on the room temperature $\left(T_{r}\right)$ and the melting temperature of the alloy $\left(T_{m}\right)$. Melting temperature is usually taken as the solidus temperature for the metal alloys. In the current case, the temperature $(T)$ is assumed to be equal to room temperature. Hence, no temperature relation contributes to the yield stress computation in this study. $\dot{\varepsilon}^{*}$ relates the effective plastic strain rate $\left(\frac{\grave{y}}{\varepsilon_{p}}\right)$ with the reference strain rate $\left(\dot{\varepsilon}_{0}\right)$ and represented by the following formula $\ddot{\varepsilon}=\frac{\bar{\varepsilon}_{p}}{\dot{\varepsilon}_{0}}$. Moreover, stress triaxility is considered regarding the ductile damage characteristics of mild steel due to the exerted pressure on it [15, 19]. The compressive, tensile, and shear stresses correspond to negative, positive, and zero triaxialities, respectively [15].

$$
\sigma_{y}=\left(A+B \bar{\varepsilon}_{p}^{n}\right)\left(1+C \operatorname{Cn}\left(\dot{\varepsilon}^{*}\right)\right)\left(1-\left(T^{*}\right)^{m}\right)
$$

Table 2. Ductile Damage Model of Mild Steel [18]

\begin{tabular}{|c|c|c|c|}
\hline Failure Strain & 1.2 & Strain Rate & 0.0001 \\
\hline Stress Triaxiality & 0.333 & Displacement at Failure & 0.0001 \\
\hline
\end{tabular}

Due to laminated nature of fiber reinforced composite plate, intralaminar and interlaminar failure analyses are performed in the frame of Hashin damage criteria and quadratic nominal stress criterion with Benzeggagh-Kenane fracture criterion, respectively. The elastic material properties andHashin damage model parameters for the unidirectional E-glass fiber reinforced composite material are given in Table 3 and 4, respectively [20]. For the intralaminar damage analysis, the built-in model of Hashin damage criteria in Abaqus, which based on quadratic polynomials of stresses, is referred accordingly [21]. Four damage initiation modes in terms of (1) tensile fiber failure mode, (2) compressive fiber failure mode, (3) tensile matrix failure mode, and (4) compressive matrix failure mode are introduced from equation 2 to 5 concerning Hashin's damage criteria [22]. Here, $S$ is the longitudinal shear strength (in-plane shear strength) and $S^{T}$ is the transverse shear strength (out-of-plane shear strength). Rest of the material parameters are mentioned in Table 4.

Tensile fiber failure mode: $\sigma_{11}>0$

$$
\left(\frac{\sigma_{11}}{X^{t}}\right)^{2}+\left(\frac{\tau_{12}}{S}\right)^{2} \geq 1
$$

Compressive fiber failure mode: $\sigma_{11}<0$

$$
\left(\frac{\sigma_{11}}{X^{c}}\right)^{2} \geq 1
$$

Tensile matrix failure mode: $\sigma_{22}>0$

$$
\left(\frac{\sigma_{22}}{Y^{t}}\right)^{2}+\left(\frac{\tau_{12}}{S}\right)^{2} \geq 1
$$

Compressive matrix failure mode: $\sigma_{22}<0$

$$
\left(\frac{\sigma_{22}}{2 S^{T}}\right)^{2}+\frac{\sigma_{22}}{Y^{c}} \times\left[\left(\frac{Y^{t}}{2 S^{T}}\right)^{2}-1\right]+\left(\frac{\tau_{12}}{S}\right)^{2} \geq 1
$$

Table 3. Elastic Properties of Unidirectional E-Glass Fiber Reinforced Polymer Composite [20]

\begin{tabular}{|c|c|c|c|}
\hline Density $\left(\mathrm{kg} / \mathrm{m}^{3}\right)$ & 1230 & $v_{13}$ & 0.3 \\
\hline $\boldsymbol{E}_{11}(\mathbf{M P a})$ & 44870 & $v_{23}$ & 0.5 \\
\hline $\boldsymbol{E}_{22}(\mathbf{M P a})$ & 12130 & $\boldsymbol{G}_{12}(\mathbf{M P a})$ & 3380 \\
\hline $\boldsymbol{E}_{33}(\mathbf{M P a})$ & 12130 & $\boldsymbol{G}_{13}(\mathbf{M P a})$ & 3380 \\
\hline $\boldsymbol{v}_{12}$ & 0.3 & $\boldsymbol{G}_{23}(\mathbf{M P a})$ & 3380 \\
\hline
\end{tabular}


Table 4. Hashin Damage Parameters of Unidirectional E-Glass Reinforced Polymer Composite [20]

\begin{tabular}{|c|c|c|c|c|c|}
\hline $\begin{array}{c}\text { Longitudinal } \\
\text { Tensile Strength, } \\
\mathrm{X}^{\mathrm{t}}(\mathrm{MPa})\end{array}$ & 1006.3 & $\begin{array}{c}\text { Transverse Tensile Stren- } \\
\text { gth, } \mathrm{Y}^{\mathrm{t}}(\mathrm{MPa})\end{array}$ & 45.95 & \multirow{2}{*}{$\begin{array}{c}\text { Longitu- } \\
\text { dinaland } \\
\text { Transverse } \\
\text { Shear } \\
\text { Strengths, S, } \\
\mathrm{S}^{\top} \text { (MPa) }\end{array}$} & \multirow[t]{2}{*}{49.51} \\
\hline $\begin{array}{l}\text { Longitudinal Com- } \\
\text { pressive Strength, } \\
\mathrm{X}^{\mathrm{c}}(\mathrm{MPa})\end{array}$ & 487 & $\begin{array}{c}\text { Transverse Compressive } \\
\text { Strength, } \mathrm{Y}^{\mathrm{c}}(\mathrm{MPa})\end{array}$ & 131.9 & & \\
\hline
\end{tabular}

The interfacial damage initiation and propagation, which leads to the delamination in composite laminates, is concerned in the frame of cohesive zone method. The cohesive failure mechanism is generally comprised of three constituents: (1) a damage initiation criterion, (2) a damage evolution law, and (3) a choice of element removal (deletion) upon reaching a completely damaged state. Damage initiation refers to the beginning of degradation of the response of a material point and it could be modeled by referring the quadratic nominal stress criterion. The damage initiation is considered when either the normal stress $\left(t_{n}\right)$, the in-plane shear stress $\left(t_{s}\right)$ or the out-of-plane shear stress $\left(t_{t}\right)$ exceed the predefined normal strength $\left(t_{n}^{0}\right)$, in-plane shear strength $\left(t_{s}^{0}\right)$ or out-of-plane shear strength $\left(t_{t}^{0}\right)$. It is quantified by a quadratic nominal stress ratio that reaches a value of one. Damage evolution model is studied in the frame of Benzeggagh-Kenane law [23] which requires the use of the interfacial fracture energy $\left(G_{\mathrm{cn}}, G_{\mathrm{cs}}, G_{\mathrm{ct}}\right)$ of the composite laminate in each direction as well. Both the damage initiation and evolution models are available as built-in models in Abaqus/ Explicit v6.19. Table 5 represents the data used for the delamination modeling.

Table 5. The Delamination Model Parameters [20]

\begin{tabular}{|c|c|c|}
\hline $\begin{array}{c}\text { Elastic proper- } \\
\text { ties }\end{array}$ & $\begin{array}{c}\text { Damage Initiation (Quadra- } \\
\text { tic Nominal Stress Criterion) }\end{array}$ & $\begin{array}{c}\text { Damage Evolution (Ben- } \\
\text { zeggagh-Kenane Fracture } \\
\text { Criterion) }\end{array}$ \\
\hline$K_{n n}=12130 \mathrm{MPa}$ & $t_{n}^{0}=45.95 \mathrm{MPa}$ & $G_{c n}=0.98 \mathrm{~J} / \mathrm{mm}^{2}$ \\
\hline$K_{s s}=3380 \mathrm{MPa}$ & $t_{s}^{0}=49.51 \mathrm{MPa}$ & $G_{c s}=3.71 \mathrm{~J} / \mathrm{mm}^{2}$ \\
\hline$K_{t t}=3380 \mathrm{MPa}$ & $t_{t}^{0}=49.51 \mathrm{MPa}$ & $G_{c t}=3.71 \mathrm{~J} / \mathrm{mm}^{2}$ \\
\hline
\end{tabular}

Three-dimensional cohesive elements are used to mesh the potential damage zone of the composite plate (i.e., between composite layers). The elastic behavior of cohesive element is based on the traction-separation law, thus cohesive elements use nominal stress and strain measures that are calculated at the integration points according to this law. The representative linear elastic behavior could be formulated in each direction (i.e., normal $(n)$, in-plane $(s)$, out-of-plane $(t)$ ) by using traction vector $\left(\left[t_{\mathrm{i}}\right]\right.$ where $\left.i=n, s, t\right)$ and separation vector $\left(\left[\delta_{\mathrm{i}}\right]\right.$ where $\left.i=n, s, t\right)$ in relation with interface stiffness $\left(\left[K_{\mathrm{ij}}\right]\right.$ where $i, j=n, s, t$ with keeping in mind the symmetric elastic stiffness relation) as given in Equation 6. As a definition, the nominal stresses are the force components divided by the original area at each integration point, while the nominal strains are the separations divided by the original thickness at each integration point. The constitutive thickness of the cohesive elements is artificially set to zero. Hence, the nominal strain $\left(\left[\varepsilon_{\mathrm{i}}\right]\right.$ where $\left.i=n, s, t\right)$ is equal to the relative displacements $\left(\left[\delta_{\mathrm{i}}\right]\right.$ where $\left.i=n, s, t\right)$ of the top and bottom faces across the interface. The off-diagonal terms are not defined in the current study. However, fully coupled elastic behavior could be studied unless there is suitable data for it.

$$
\left[\begin{array}{c}
t_{n} \\
t_{s} \\
t_{t}
\end{array}\right]=\left[\begin{array}{lll}
K_{n n} & K_{n s} & K_{n t} \\
K_{n s} & K_{s s} & K_{s t} \\
K_{n t} & K_{s t} & K_{t t}
\end{array}\right]\left[\begin{array}{l}
\varepsilon_{n} \\
\varepsilon_{s} \\
\varepsilon_{t}
\end{array}\right]
$$

The interaction between steel projectile and glass fiber reinforced laminated composite plate is assumed to be frictionless and general contact algorithm is adopted accordingly.

\section{RESULTS AND DISCUSSION}

The interlaminar and intralaminar failure analyses of glass fiber reinforced composite plate owing to cylindro-conical mild steel projectile impact at striking velocity of $54 \mathrm{~m} / \mathrm{s}$ are performed via Abaqus/Explicit v6.19. Intralaminar damage analysis is performed by using Hashin failure criteria. Cohesive failure mechanism for interlaminar debonding in composite laminate is modeled by inserting cohesive elements between the potential damage region of the adjacent layers. Once the interlaminar toughness, the stiffness of the bulk constituents and the accuracy of predictions/computational cost are considered, the shape of the softening curve (damage evolution model) is referred to be based on linear softening law [23]. The interlaminar debonding is analyzed using mixed-mode failure data in the frame of Benzeggagh-Kenane mixed-mode fracture energy criteria with an exponent of $\eta=1.40$ as defined in reference [20]. The SC8R and COH3D8 elements possess the same nodal degrees of freedom; stress could be transmitted between layers without causing hinge formation. Matrix inhomogeneity is not studied in the possible non-uniform initiation and propagation of damage.

The use of two finite element models revealed the effect of interface properties on stress distribution, damage initiation and propagation owing to impact loading (Table 6). The maximum von Mises stress values obtained indicated that in the absence of cohesive zone modeling, those values do not exhibit significant variations from Analysis 1 to 10. However, the differences among those stress values are found larger when the approximate global mesh size of bullet change rather than that in plate. Hence, approximate global mesh size of the bullet is found more effective on those von Mises stress values. Slightly lower stresses are found once the interface properties are defined between the adjacent layers of the composite plate. Studying the delamination mode of failure notably improved the model given in literature besides predefined material stress/strain limit damage model[15].

By excluding cohesive zone modeling, Hashin fiber compressive failure criterion is satisfied for the first five plies of the both composite plate at given mesh densities (Figure 2). Hence, the first five layers of the composite laminates could not be loaded any longer. Identical behavior is observed in both analyses since Hashin fiber compressive failure criterion is assured on the strike face of the plate. 


\begin{tabular}{|c|c|c|c|c|c|c|}
\hline $\begin{array}{c}\text { Analysis } \\
\text { No }\end{array}$ & Ply-1 & Ply-2 & Ply-3 & Ply-4 & Ply-5 & Ply-6 \\
\hline 1 & 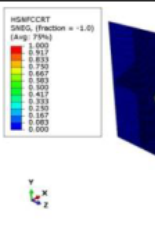 & 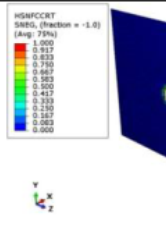 & 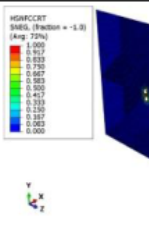 & 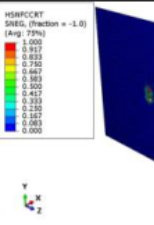 & 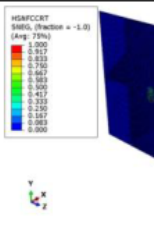 & 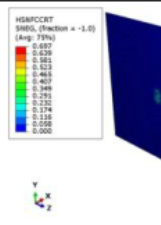 \\
\hline 10 & 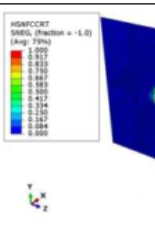 & 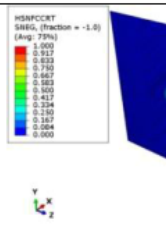 & 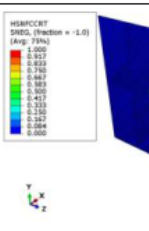 & 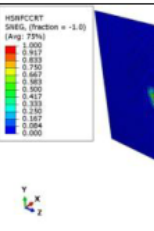 & 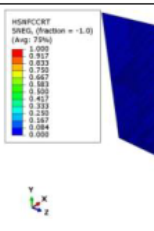 &  \\
\hline
\end{tabular}

Figure 2. Intralaminar Failure Analysis of Composite Plate for Analysis 1 and 10

Table 6. Maximum von Mises Stress Depending on the Model Parameters

\begin{tabular}{|c|c|c|c|c|}
\hline Analysis Type & \multicolumn{2}{|c|}{$\begin{array}{l}\text { Approximate Global Mesh } \\
\text { Size (B for Bullet, P for Plate) }\end{array}$} & $\begin{array}{c}\text { Analysis } \\
\text { No }\end{array}$ & $\begin{array}{c}\text { Maximum } \\
\text { von Mises } \\
\text { Stress }(\mathrm{MPa})\end{array}$ \\
\hline \multirow{10}{*}{ Without Cohesive } & \multirow{5}{*}{$B=1 \mathrm{~mm}$} & $P=1 \mathrm{~mm}$ & 1 & 826.669 \\
\hline & & $P=1.25 \mathrm{~mm}$ & 2 & 862.368 \\
\hline & & $P=1.50 \mathrm{~mm}$ & 3 & 854.800 \\
\hline & & $P=1.75 \mathrm{~mm}$ & 4 & 859.290 \\
\hline & & $\mathrm{P}=2 \mathrm{~mm}$ & 5 & 794.357 \\
\hline & \multirow{4}{*}{$\mathrm{P}=1 \mathrm{~mm}$} & $B=1.25 \mathrm{~mm}$ & 6 & 814.865 \\
\hline & & $B=1.50 \mathrm{~mm}$ & 7 & 972.899 \\
\hline & & $B=1.75 \mathrm{~mm}$ & 8 & $N / A^{*}$ \\
\hline & & $\mathrm{B}=2 \mathrm{~mm}$ & 9 & 792.612 \\
\hline & $B=2 \mathrm{~mm}$ & $\mathrm{P}=2 \mathrm{~mm}$ & 10 & 759.009 \\
\hline \multirow{10}{*}{ With Cohesive } & \multirow{5}{*}{$\mathrm{B}=1 \mathrm{~mm}$} & $P=1 \mathrm{~mm}$ & 11 & 776.238 \\
\hline & & $P=1.25 \mathrm{~mm}$ & 12 & 776.010 \\
\hline & & $P=1.50 \mathrm{~mm}$ & 13 & 774.866 \\
\hline & & $P=1.75 \mathrm{~mm}$ & 14 & 774.611 \\
\hline & & $\mathrm{P}=2 \mathrm{~mm}$ & 15 & 772.810 \\
\hline & \multirow{4}{*}{$P=1 \mathrm{~mm}$} & $B=1.25 \mathrm{~mm}$ & 16 & 764.813 \\
\hline & & $B=1.50 \mathrm{~mm}$ & 17 & 763.092 \\
\hline & & $\mathrm{B}=1.75 \mathrm{~mm}$ & 18 & 748.375 \\
\hline & & $\mathrm{B}=2 \mathrm{~mm}$ & 19 & 746.645 \\
\hline & $\mathrm{B}=2 \mathrm{~mm}$ & $\mathrm{P}=2 \mathrm{~mm}$ & 20 & 742.162 \\
\hline
\end{tabular}

${ }^{*} \mathrm{~N} / \mathrm{A}$ : Not available (aborted due to excessive element distortion) In the presence of cohesive zone modeling, Hashin fiber compressive failure criterion, matrix compressive criterion and overall value of the scalar damage variable of the first two plies are shown in Figure 3. For the first layer of the composite plate, only Hashin matrix failure criterion is found independent of mesh sizes (i.e., plate and bullet meshed with $1 \mathrm{~mm}$ and $2 \mathrm{~mm}$ elements). The cohesive element outputs three force resultants: in plane shear resultant, the orthogonal in plane shear resultant, and the normal stress resultant. Depending on the results of scalar degradation variable, delamination is said to be occurred between the first and the second plies of the composite plate once both bullet and plate are meshed with $2 \mathrm{~mm}$ elements.

It is essential to present the computational cost once the fi- nite element model is revised by including additional model parameters. The computational cost of both analyses identified by referring CPU time and wall clock time as shown in Table 7. All of the computational analysis is performed on an Intel Core i5 2.4 GHz processor with $16 \mathrm{~GB}$ of installed ram. It is obvious that the analyses with interface model take more time than the sole intralaminar analysis. However, none of those analyses have taken more than 110 seconds. The longest time to complete computational analysis is found around $75 \mathrm{~s}$ without including delamination analysis. Interface debonding in composite laminate is obtained with small computational effort.

\section{CONCLUSIONS}

Conical nose shaped cylindrical shank projectile impact on an E-glass fiber reinforced polymer composite plate is studied in the frame of intralaminar and interlaminar failure analyses. Numerical convergence is satisfied by gradually varying mesh size upon comparison with literature data. Elements that are used to mesh projectile and plate have the same active nodes. The stress developed in composite plate due to impact loading possessed similar values in each modeling approach. However, implementation of cohesive zone modeling revealed the presence of delaminated layer. It is shown that delamination could be captured with small computational effort in terms of CPU time and wall clock time. The relative displacement between the crack faces of the composite plies have not modeled including frictional opposing loads. Hence, frictional contact condition may be defined in order to track the effect of frictional forces upon fully degradation of cohesive elements.

In further analysis, the equation of state model and Chang-Chang damage model could be implemented in order to observe the impact behavior of plate under the same restraint conditions. The effect of elevated temperatures on ductile failure of mild steel projectile would be evaluated as well. Furthermore, numerical analyses may be experimentally va- 


\begin{tabular}{|c|c|c|c|c|}
\hline Analysis & Ply-1 (HSNFCCRT) & Ply-1 (HSNMCCRT) & Cohesive zone & Ply-2 (HSNFCCRT) \\
\hline 11 & 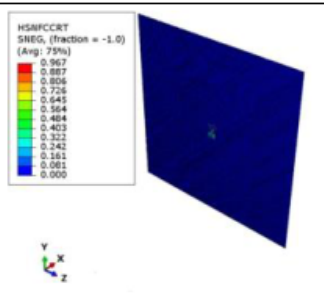 & 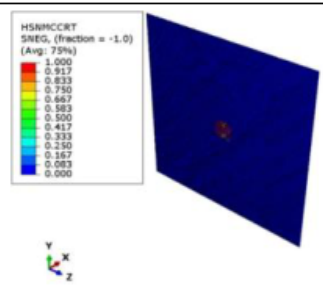 & 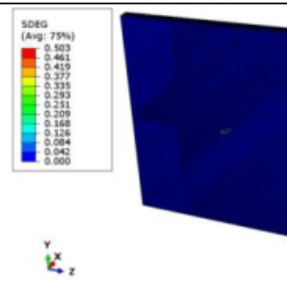 & 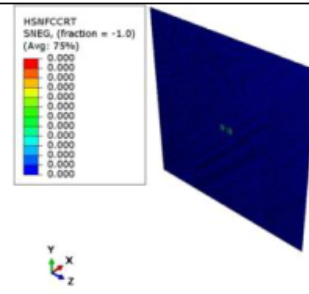 \\
\hline 20 & 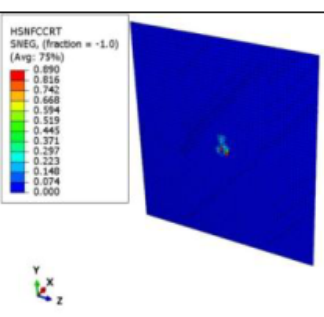 & 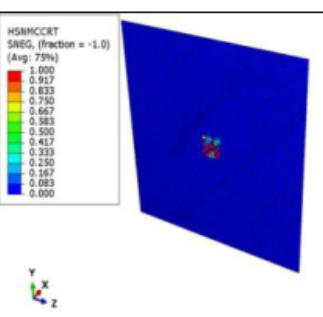 & 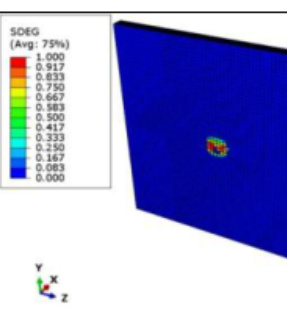 & 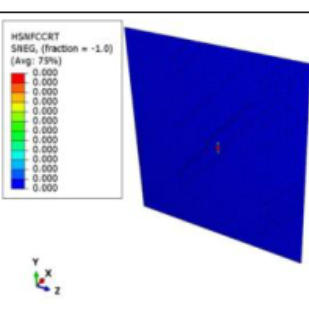 \\
\hline
\end{tabular}

Figure 3. Intralaminar and Interlaminar Failure Analysis of Composite Plate for Analysis 11 and 20

Table 7. Comparison of Computational Cost Regarding CPU Time and Wall Clock Time

\begin{tabular}{|c|c|c|c|c|c|c|c|}
\hline \multicolumn{4}{|c|}{ Without Cohesive Zone } & \multicolumn{4}{|c|}{ With Cohesive Zone } \\
\hline $\begin{array}{l}\text { Approximate } \\
\text { Global Mesh } \\
\text { Size of Bullet } \\
(\mathrm{mm})\end{array}$ & $\begin{array}{l}\text { Approximate } \\
\text { Global Mesh } \\
\text { Size of Plate } \\
(\mathrm{mm})\end{array}$ & $\begin{array}{c}\text { Total CPU Time } \\
\text { (s) }\end{array}$ & $\begin{array}{c}\text { Wall Clock Time } \\
\text { (s) }\end{array}$ & $\begin{array}{l}\text { Approximate } \\
\text { Global Mesh } \\
\text { Size of Bullet } \\
\quad(\mathrm{mm})\end{array}$ & $\begin{array}{l}\text { Approximate } \\
\text { Global Mesh } \\
\text { Size of Plate } \\
(\mathrm{mm})\end{array}$ & $\begin{array}{c}\text { Total CPU Time } \\
\text { (s) }\end{array}$ & $\begin{array}{c}\text { Wall Clock Time } \\
\text { (s) }\end{array}$ \\
\hline 1 & 1 & 74.4 & 75 & 1 & 1 & 98.5 & 99 \\
\hline 1 & 1.25 & 52.3 & 53 & 1 & 1.25 & 65.4 & 67 \\
\hline 1 & 1.5 & 24 & 24 & 1 & 1.5 & 79.7 & 81 \\
\hline 1 & 1.75 & 19.9 & 20 & 1 & 1.75 & 63.4 & 64 \\
\hline 1 & 2 & 16.6 & 16 & 1 & 2 & 49.9 & 51 \\
\hline 1.25 & 1 & 41.2 & 42 & 1.25 & 1 & 109.7 & 110 \\
\hline 1.5 & 1 & 39.8 & 40 & 1.5 & 1 & 93.5 & 95 \\
\hline 1.75 & 1 & $N / A^{*}$ & $N / A^{*}$ & 1.75 & 1 & 92.9 & 94 \\
\hline 2 & 1 & 40 & 40 & 2 & 1 & 93.2 & 94 \\
\hline
\end{tabular}

*N/A: Not available (aborted due to excessive element distortion)

lidated to improve the finite element model accordingly. A friction model such as Coulomb friction with appropriate friction coefficients would be defined between delaminated layers especially when working with various stacking orientations. In order to observe the variation of threat shape on the impact behavior of composite plate, ogival and blunt tip projectiles would be used instead of conical projectile. Polymer composite plate could be modeled by using metal layers to contribute protective structural application in aerospace industry.

\section{REFERENCES}

[1] Carlucci, D.E., Jacobson, S.S. (2014). Ballistics Theory and Design of Guns and Ammunition. CRC Press.

[2] Hazell, P.j. (2016). Armour: Materials, Theory, and Design. CRC Press.

[3] Vincent, J.M. \& Di Maio, M.D. (2016). Gunshot Wounds. CRC Press.

[4] Børvik, T., Dey, S., Clausen, A.H. (2009). Perforation resistance of five different high-strength steel plates subjected to small-arms projectiles. International Journal of Impact Engineering, 36(7): 948 - 964,
DOI:10.1016/j.jimpeng.2008.12.003

[5] Crouch, I.G., Appleby-Thomas, G., Hazell, P.J. (2015). A study of the penetration behaviour of mild-steel-cored ammunition against boron carbide ceramic armours. International Journal of Impact Engineering, 80: 203 - 211, DOl:10.1016/j.ijimpeng.2015.03.002

[6] Nilakantan, G. \& Nutt, S. (2018). Effects of ply orientation and material on the ballistic impact behavior of multilayer plain-weave aramid fabric target. Defence Technology, 14(3): $165-178$, DOI:10.1016/j.dt.2018.01.002

[7] Herakovich, C.T. (1998). Mechanics of Fibrous Composites. Wiley.

[8] Bandaru, A.K., Vetiyatil, L., Ahmad, S. (2015). The effect of hybridization on the ballistic impact behavior of hybrid composite armors. Composites Part B: Engineering, 76: 300 - 319, DOI: 10.1016/j.compositesb.2015.03.012

[9] Crouch, I. (2017). The Science of Armor Materials. Elsevier.

[10] Silberschmidt, V. V. (2016). Dynamic Deformation, Damage and Fracture in Composite Materials and Structures. Elsevier.

[11] Klinkrad, H. (2005). Space Debris - Models and Risk Analysis. Springer-Verlag. 
[12] Serrontino, L., Bellini, C., Corrado, A., Polini, W., Arico, R. (2015). Ballistic performance evaluation of composite laminates in Kevlar 29. Procedia Engineering, 88: 255 - 262, DOI: 10.1016/j.proeng.2015.06.048

[13] Roberts, G. D., Pereira, J. M., Revilock Jr, D. M., Binienda, W. K., Xie, M., Braley, M. (2005). Ballistic impact of braided composites with a soft projectile. Journal of Aerospace Engineering, 18(1): 3-7, DOI:10.1061/(ASCE)0893-1321(2005)18:1(03)

[14] Zukas, J.A. (2004). Introduction to Hydrocodes. Elsevier.

[15] Rao, C. L., Narayanamurthy, V., Simha, K.R.Y. (2016). Applied Impact Mechanics. Wiley.

[16] Liu, G.R., Quek, S.S. (2014). The Finite Element Method. Elsevier.

[17] Rao, S. (2008). Numerical Simulation of Ballistic Impact on Composite Targets. M.Tech Thesis, IIT Madras, India.

[18] Jankowiak, T., Rusinek, A., Kpenyigba, K., Pesci, R. (2014). Ballistic behavior of steel sheet subjected to impact and perforation. Steel and Composite Structures, 16(6): 595-609, DOl: 10.12989/ scs.2014.16.6.595

[19] Rosenberg, Z., Dekel, E. (2012). Terminal Ballistics. Springer.

[20] Perillo, G., Jørgensen, J. (2016). Numerical/Experimental Study of the Impact and Compression After Impact on GFRP Composite for Wind/Marine Applications. Procedia Engineering, 167: 129-137. DOI:10.1016/j.proeng.2016.11.679

[21] Yavuz, H. (2019). Materials selection for aircraft skin panels by integrating multiple constraints design with computational evaluations. Procedia Structural Integrity, 21: 112-119, DOI: 10.1016/j. prostr.2019.12.092

[22] Hashin, Z., Herakovich, C.T. (1983). Mechanics of Composite Materials. Pergamon Press.

[23] Sørenson, B. T. (2010). Cohesive Laws for Assessment of Materials Failure: Theory, Experimental Methods and Application. Ph.D. Thesis, DTU, Denmark. 